\title{
Recuperación de activos en el sistema penal alemán: luces y sombras del actual régimen de decomiso de ganancias ${ }^{1}$
}

\author{
Asset Recovery in the German Criminal Justice System: \\ Lights and Shadows of the New Regulation of the \\ Confiscation of the Proceeds Of Crime
}

Ana E. Carrillo del Teso ${ }^{2}$

Universidad de Salamanca - España ana_cdt@usal.es http://orcid.org/0000-0002-1245-2499

\begin{abstract}
Resumen: En este artículo pretendemos examinar los aspectos más notables de la ley para la reforma de la recuperación de activos penal (Gesetz zur Reform der strafrechtlichen Vermögensabschöpfung), en vigor desde el 1 de julio de 2017, con la que el legislador alemán actualizó el régimen del decomiso tanto en su vertiente sustantiva como procesal. Dada la extensión de esta reforma, debido a su carácter integral, nos centraremos en la modificación del decomiso de ganancias, esencia de la política criminal de recuperación de activos. En concreto, analizaremos aquellos puntos de la reforma destacados por el propio legislador en el proyecto de ley, dividiéndolos entre aquellos que pueden parecer más
\end{abstract}

1 Este trabajo ha sido elaborado gracias a una ayuda de la Fundación Manuel Serra Domínguez, convocatoria de 2018, para la realización de una estancia de investigación en el Institut für Strafrecht und Strafprozessrecht, Abt. III: Deutsches und Ausländisches Strafrecht und Strafprozessrecht de la Albert-Ludwigs-Universität de Friburgo (Alemania). Igualmente, se enmarca en los proyectos de investigación: DER2016-79895-P "La reforma del decomiso y la recuperación de activos derivados del delito" (Ministerio de Economía, Industria y Competitividad); y SA129G18 "La armonización normativa del decomiso y de la recuperación de activos en la Unión Europea” (Junta de Castilla y León).

2 Profesora Ayudante Doctora de Derecho Procesal. Departamento de Derecho Administrativo, Financiero y Procesal. Universidad de Salamanca. 
positivos ("las luces") y aquellos más controvertidos ("las sombras"). En el primer grupo encuadraremos lo referente a la posición de las víctimas, las medidas para la descongestión del proceso penal y la regulación del cálculo de las ganancias decomisables; en el segundo, el nuevo ámbito del decomiso ampliado y el decomiso independiente de bienes de origen incierto.

Palabras-clave: recuperación de activos; decomiso de ganancias; decomiso ampliado; procedimiento de decomiso; Alemania.

ABSTRACT: In this paper, we intend to examine the highlights of the German Asset Recovery Act (Gesetz zur Reform der strafrechtlichen Vermögensabschöpfung), in force since 1st July 2017. It is a comprehensive law, with which the German legislator updated the confiscation regime in both its substantive and procedural aspects. Given the extent of this reform, we will focus on the confiscation of proceeds of crime, as it is the essence of asset recovery. Specifically, we will analyse those points of the reform emphasized by the legislator in the draft act. To this end, we will divide them between those that may seem more positive and those that are more controversial. In the first group, we will frame what refers to the position of the victims, the innovations for the decongestion of the criminal process and the regulation of the estimate of the proceeds. In the second group, we will study the new scope of the extended confiscation and the independent confiscation of assets of uncertain origin.

KEYWORDS: asset recovery; confiscation of the proceeds of crime; extended confiscation; confiscation proceedings; Germany.

Contenido: Introducción; 1 . Consideraciones previas sobre la política de recuperación de activos; 2 . Notas generales sobre la reforma y el decomiso en Alemania; 3. Las "luces" de la reforma: soluciones a antiguos problemas prácticos; 3.1. Las víctimas ante el decomiso; 3.2. La matización del principio de ganancias brutas; 3.3. Cuestiones procesales: separación del procedimiento de decomiso y principio de oportunidad; 4. Las "sombras" de la reforma: aspectos controvertidos; 4.1. La ilimitada potestad de decomiso ampliado; 4.2. Los nuevos perfiles del decomiso sin condena: el decomiso independiente de bienes de origen incierto; Conclusiones; Bibliografía. 


\section{INTRODUCCIÓN}

El estudio del actual régimen alemán para la recuperación de activos criminales supone un reto grato, aunque difícil. En Alemania tuvo lugar en el año 2017 una reforma integral que modificó por completo la regulación del decomiso y que impactó tanto en el articulado penal (Strafgesetzbuch, en adelante StGB) como en el procesal penal (Strafprozeßordnung, en adelante StPO). Pese a que con esta reforma se cumplía, si bien algo tarde $^{3}$, el obligatorio trámite de trasponer la Directiva 2014/42/UE ${ }^{4}$, esa no era ni la principal finalidad ni la preocupación esencial del legislador. Más bien, lo que pretendía era resolver determinados problemas que se venían arrastrando en la práctica, así como colmar ciertas lagunas jurídicas. En concreto, se buscaba racionalizar la relación del decomiso con la indemnización de las víctimas, permitir a los tribunales aplazar la orden de decomiso a una etapa posterior a la sentencia condenatoria, extender el ámbito del decomiso ampliado y establecer una base jurídica para el decomiso sin condena de bienes de origen desconocido ${ }^{5}$.

Este ánimo de solucionar problemas aplicativos parece un motivo de peso para la elaboración de la norma que vamos a analizar: se afirma que los jueces no decretaban el decomiso por su complejidad ${ }^{6}$, por la incapacidad o inaplicabilidad del régimen anterior ${ }^{7}$. Pero según algunos autores la clave reside realmente en la especial voluntad política de la Gran

3 Según la Corrección de errores de la Directiva 2014/42/UE del Parlamento Europeo y del Consejo, de 3 de abril de 2014, sobre el embargo y el decomiso de los instrumentos y del producto del delito en la Unión Europea (DOUE L 127 de 29 de abril de 2014), la fecha límite para la trasposición era el 4 de octubre de 2016.

4 Directiva 2014/42/UE del Parlamento Europeo y del Consejo, de 3 de abril de 2014, sobre el embargo y el decomiso de los instrumentos y del producto del delito en la Unión Europea (DOUE L 127 de 29 de abril de 2014, pp. 39-50).

5 BT-Drucks. 18/9525, pp. 2-3. BÖSE, Martin; WEYER, Vera. Germany. Improving Confiscation Procedures in the European Union. Nápoles, 2019, p. 250.

6 BT-Drucks. 18/9525, p. 3. Hay un ejemplo reciente en el LG Bonn, Beschluss v. 17.03.2020 - $62 \mathrm{KLs} 1 / 19$, del que hablaremos infra.

7 Una sólida crítica del anterior sistema en MEYER, Frank. "Reformiert die Rückgewinnungshilfe!” - Denkanstöße für eine Generalüberholung der Vermögensabschöpfung. Zeitschrift für die gesamte Strafrechtswissenschaft, Berlín, v. 127, n. 2, 2015, p. 241-283. 
Coalición que gobernaba en ese momento por ponerse al día con la política criminal de recuperación de activos ${ }^{8}$-que se estimaba infravalorada en Alemania9 ${ }^{9}$, en definitiva, por hacer efectiva la máxima de que el delito no debe resultar provechoso ${ }^{10}$, a la que en algún documento explicativo del proyecto de ley se le dio el rango de principio general del ordenamiento, al mismo nivel que el principio de igualdad ante la ley ${ }^{11}$.

Es imposible tratar de abordar por completo en el espacio del que disponemos una reforma que ha dado una nueva redacción a un total de diecisiete secciones o artículos del StGB y treinta y seis de la StPO, sin contar la reforma de la ley sobre contravenciones (Gesetz über Ordnungswidrigkeiten, OWiG), y otras tantas reformas menores sobre todas estas normas respecto a cuestiones incidentales. Dado que la política criminal de recuperación de activos se refiere esencialmente al producto del delito, vamos a centrar nuestro análisis en los grandes cambios que le afectan, dejando al margen las disposiciones sobre instrumentos y efectos del delito.

En el presente artículo nos proponemos examinar esos aspectos destacados de la reforma con una doble finalidad: por un lado, poner de relieve las dificultades que se pueden derivar en la práctica de los tribunales debido al diseño legislativo del decomiso. Por otro, traer más

8 SALIGER, Frank. Grundfragen der Vermögensabschöpfung. Zeitschrift für die gesamte Strafrechtswissenschaft, Berlín, v. 129, n. 4, 2017, p. 997

9 BT-Drucks. 18/9525, p. 1: "La ley actual no hace justicia a la gran importancia de la recuperación de activos criminales". Los datos parecen apoyar esta afirmación: la Oficina Federal de Investigación Criminal alemana (BKA) estima que el crimen organizado entre 2014 y 2018 ha causado unas pérdidas acumuladas de 2.869 millones de euros. Las ganancias del delito que se pudieron identificar en ese periodo fueron 2.225 millones de euros, de los que solo se aseguraron cautelarmente 312 millones de euros. Bundeskriminalamt (BKA), Bundeslagebilder Organisierte Kriminalität 2018, 24.09.2020, p. 12 y 14. Si hablamos de delincuencia económica, el daño estimado solamente en 2018 asciende a 3.356 millones de euros. Bundeskriminalamt (BKA), Bundeslagebilder Wirtschaftskriminalität 2018, p. 4.

10 Lema de la estrategia de recuperación de activos en la Unión Europea desde la Comunicación de la Comisión al Parlamento Europeo y al Consejo - Productos de la delincuencia organizada: garantizar que "el delito no resulte provechoso”, COM (2008) 766 final, Bruselas, 20 de noviembre de 2008

11 Bundesministerium der Justiz und für Verbraucherschutz, Gesetzentwurf Reform der strafrechtlichen Vermögensabschöpfung - Fragen und Antworten. 
elementos al debate entre garantías y eficacia que impregna al decomiso de ganancias como herramienta para la recuperación de activos, ya que la ley alemana de 2017 es un perfecto ejemplo de la denominada vis expansiva del decomiso ${ }^{12}$.

No obstante, con carácter previo, realizaremos una serie de consideraciones sobre la política criminal de recuperación de activos, en concreto, sobre su sentido y su evolución a lo largo de las últimas décadas, para contextualizar tanto la reforma como nuestro trabajo. A continuación, comentaremos algunas cuestiones sobre la tramitación de la ley y su entrada en vigor y aplicabilidad, que han suscitado las primeras dudas sobre su compatibilidad con los principios propios de un Estado de Derecho. Esto nos lleva a hacer algunas anotaciones sobre la naturaleza y finalidad del decomiso de ganancias en la doctrina y la jurisprudencia alemanas.

Una vez que contamos con esta base, emprenderemos el examen de los puntos más significativos de la reforma, para lo que los sistematizaremos en dos grupos. En primer lugar, trataremos aquellos que, a priori. pueden parecer más positivos por solucionar ciertos problemas prácticos del decomiso en Alemania. Estos son el nuevo régimen del decomiso en relación con las víctimas, la concreción del principio de ganancias brutas y las medidas para la descongestión del proceso penal. En segundo lugar, analizaremos aquellos que han producido una mayor controversia por su discutida compatibilidad con las garantías del proceso penal: el nuevo ámbito de aplicación del decomiso ampliado y el decomiso independiente de bienes de origen incierto.

Para ello, compararemos el sentido de la nueva regulación con la anterior, contrastando la voluntad declarada del legislador en las diferentes versiones del proyecto de ley, la opinión de la doctrina y la jurisprudencia más relevante originada en el lapso de tiempo desde la aprobación de la ley.

En definitiva, nos planteamos una serie de preguntas a las que pretendemos responder: ¿cuál es el alcance de esta reforma?, ¿̇supone un cambio relevante y útil respecto a la anterior regulación?, ¿cumple con

12 MAUGERI, Anna Maria. L'irrefrenabile tendenza espansiva della confisca qualle strumento di lotta contro la criminalità organizzata. Criminalità organizzata e sfruttamento delle risorse territoriali, Milán, 2004, p. 97 y ss. 
los fines que se propone?, ¿son todos sus elementos respetuosos con los principios del proceso penal? Y, por último, ¿podemos decir que se abre una nueva etapa en las medidas para la recuperación de activos?

\section{Consideraciones preVias sobre la política de ReCuperación DE ACTIVOS}

Aunque desde los años 80, en los instrumentos internacionales elaborados contra los fenómenos delictivos que más preocupan a la comunidad internacional-como el narcotráfico o el crimen organizadose le ha dado al decomiso del producto del delito una gran importancia, la política criminal de recuperación de activos, bajo esta denominación, se ha extendido y popularizado en los últimos quince años gracias a la acción de Naciones Unidas, que marcó un hito al dedicar todo un capítulo de su Convención contra la Corrupción de 2003, comúnmente conocida como Convención de Mérida, a la materia ${ }^{13}$.

En este tipo de delitos parece especialmente necesario que los beneficios que se hayan obtenido de estas prácticas sean sustraídos de manos de los autores y reviertan en la sociedad ${ }^{14}$. Por ello, cuando hablamos de recuperación de activos stricto sensu, hacemos referencia a la repatriación de fondos de un país expoliados por la corrupción a gran escala, tendencialmente un país en vías de desarrollo, que requiere de la colaboración de otro Estado, donde se encuentran estos fondos.

La recuperación de activos, como decíamos, busca una serie de fines: por un lado, estrangular las finanzas de los delincuentes, para así evitar que los beneficios se inviertan en posteriores actividades delictivas

13 JORGE, Guillermo. Los desafíos de recuperar el producto de delitos de corrupción» Recuperación de activos de la corrupción. Buenos Aires, 2008, p. XIII y ss.

14 Directiva 2014/42/UE, considerando 35: "Los Estados miembros deben estudiar la posibilidad de tomar medidas que permitan que los bienes decomisados se utilicen con fines de interés público o con fines sociales (...)”. $\mathrm{Al}$ respecto, VETTORI, B., NICOLA, A. di. The Social Reuse of Confiscated Assets in EU Member States: From Current Experiences to an EU Policy for a "Powered-by-Citizens" Fight Against Crime. Chasing Criminal Money. Challenges and Perspectives On Asset Recovery in the EU. Oxford, 2017, p. 321 y ss. 
y que infiltren y capturen el sistema económico legal; por otro lado, evitar que el delito resulte provechoso y así desincentivar la comisión de delitos con ánimo de lucro; sin olvidarnos del restablecimiento del orden patrimonial lícito. Por esto es una estrategia útil para cualquier tipo de delincuencia "del beneficio"15, y se ha incidido especialmente en su aplicación en el ámbito del crimen organizado (de hecho, este fue el origen de la estrategia de privación de bienes en la legislación norteamericana a comienzos de los años 70 del pasado siglo ${ }^{16}$ ).

De esta manera, se ha ampliado la expresión "recuperación de activos" con la que ya no solo nos referimos a esta concreta política criminal anticorrupción, sino a la sustracción de las ganancias de cualquier tipo de criminalidad lucrativa, sentido en el que se define como el retorno de los bienes procedentes de un delito ocultos en el extranjero ${ }^{17}$.

La Unión Europea ha abrazado con efusividad esta política criminal, plasmada, en la etapa post-Lisboa, en la Comunicación de la Comisión al Parlamento Europeo y al Consejo - Productos de la delincuencia organizada: garantizar que "el delito no resulte provechoso". En la Directiva 2014/42/UE compele a los Estados miembros a incorporar a sus ordenamientos las principales modalidades de aplicación de esta figura: decomiso directo, decomiso por valor equivalente, decomiso sin condena, decomiso ampliado y decomiso de terceros.

15 Expresión tomada de MENDITTO, Francesco. Le confische nella prevenzione e nel contrasto alla criminalità "da profitto" (mafie, corruzione, evasione fiscale). Appunti a margine di alcune proposte di modifica normativa. Diritto Penale Contemporaneo, 2 Febbraio, 2015, p. 1.

16 Estados Unidos introdujo el decomiso como consecuencia penal (criminal forfeiture) en dos normas: la Continuing Criminal Enterprise Act (CCE) y la Racketeer Influenced and Corrupt Organizations Act (RICO). Junto a la forma penal, no tardó en preverse una forma civil de decomiso o civil forfeiture en la Comprehensive Drug Abuse Prevention and Control Act de 1970, que introdujo un procedimiento in rem, sin ningún tipo de vinculación a la condena a los responsables de un delito. Esta forma de decomiso civil se convirtió en el principal instrumento de las políticas de "tolerancia cero" contra el narcotráfico en las administraciones de Reagan y Bush a partir de 1988.

17 FATF-GAFI. Best practices on confiscation (Recommendations 4 and 38) and a framework for ongoing work on asset recovery, 2012, p. 1: “The term asset recovery means the return or repatriation of the illicit proceeds, where those proceeds are located in foreign countries". 
Si quisiéramos definir etapas en la evolución en materia de decomiso ${ }^{18}$, al menos desde que se generalizó el derecho penal liberal, en una primera etapa tras la abolición de las penas de confiscación general, nos encontramos con un decomiso mínimo, que solo afecta a los bienes muy directamente unidos al delito, especialmente instrumentos y efectos.

En una segunda etapa (que podríamos ubicar en las tres últimas décadas del siglo XX) como respuesta a la aparición de formas de criminalidad organizadas, con un potencial dañino al que ese derecho penal liberal no tenía capacidad para hacer frente, empiezan a aparecer lo que se denominaron "modernas formas de decomiso", aunque acotadas, tanto en tipología (sobre todo hablamos en ese momento de decomiso ampliado y decomiso por valor equivalente), como en su ámbito de aplicación, ya que se solían reservar para este tipo de delincuencia, en concreto para la actividad de asociaciones de tipo mafioso, y para los delitos de narcotráfico ${ }^{19}$.

En una tercera etapa, entre las dos grandes normas de la Unión Europea para la aproximación de las regulaciones de decomiso de los Estados miembro, la Decisión Marco 2005/212/JAI ${ }^{20}$ y la Directiva 2014/42/UE, se fueron ampliando los contornos de esta figura. La cuarta etapa, hablando del contexto europeo, surge de la trasposición de esa última norma, una norma con una estructura simple y de exigencias mínimas, que los Estados han hipertrofiado al trasladarla a sus respectivos ordenamientos $^{21}$. Ese parece ser también el caso de Alemania.

18 Ampliamente en RODRÍGUEZ GARCÍA, Nicolás. El decomiso de activos ilícitos. Cizur Menor, 2017.

19 Estas medidas, junto al blanqueo de capitales, eran objeto de regulación en el art. 5 de la Convención de las Naciones Unidas contra el tráfico ilícito de estupefacientes y sustancias sicotrópicas, hecha en Viena el 20 de diciembre de 1988. En concreto en el art. 5.7 aparece por primera vez la inversión de la carga de la prueba respecto del origen lícito del supuesto producto u otros bienes sujetos a decomiso, germen de la facultad de decomiso ampliado.

Decisión Marco 2005/212/JAI del Consejo de 24 de febrero de 2005 relativa al decomiso de los productos, instrumentos y bienes relacionados con el delito (DOUE L núm. 68, de 15 de marzo de 2005).

21 Sirva de ejemplo la trasposición en España, en AGUADO CORREA, Teresa. Decomiso: denominador común de la lucha eficaz contra el blanqueo de capitales, la delincuencia organizada y la financiación del terrorismo en la Unión Europea. El lavado de activos y la persecución de bienes de origen ilícito. Bogotá, 


\section{Notas generales Sobre la Reforma y el decomiso en Alemania}

Antes de acometer la tarea que nos hemos propuesto abordar, conviene hacer algunas puntualizaciones previas sobre la nueva regulación. La ley para la reforma de la recuperación de activos penal (Gesetz zur Reform der Strafechtlichen Vermögensabschöpfung ${ }^{22}$ ), aprobada el 13 de abril de 2017, entró en vigor el 1 de julio de ese mismo año. La tramitación fue bastante rápida: el 12 de agosto de 2016 se presentó el proyecto, siguiendo el procedimiento para la tramitación urgente de leyes del art. 76.2, cuarto inciso, de la ley fundamental (Grundgesetz für die Bundesrepublik Deutschland, GG). Se buscaba su aplicación inmediata, así que la nueva regulación se hizo aplicable a cualquier delito sobre el que no hubiera recaído aún ninguna decisión judicial, independientemente de que se hubiera cometido antes de su entrada en vigor (art. 316h de la ley introductoria al StGB, Einführungsgesetzes zum Strafgesetzbuch, EGStGB). Ambos elementos, su rápida tramitación y su aplicabilidad inmediata, obligaron a una actualización contrarreloj de doctrina y operadores jurídicos, especialmente de los miembros del Ministerio Fiscal ${ }^{23}$.

Sin embargo, resulta más relevante la división de opiniones que el art. 316h EGStGB ha provocado en la jurisprudencia ${ }^{24}$. Mientras que algunos

2017, p. 125-168. Ver también: GÓMEZ RIVERO, María del Carmen. La recuperación de activos procedentes del delito: ¿hacia el delito de enriquecimiento ilícito? Cuadernos de política criminal, n. 121, p. 201-260, 2017.

22 Bundesgesetzblatt Jahrgang 2017 Teil I Nr. 22, ausgegeben zu Bonn am 21. April 2017, pp. 872-894.

23 KORTE, Matthias. Grundzüge der Reform der Vermögensabschöpfung, Neue Zeitschrift für Wirtschafts-, Steuer- und Unternehmensstrafrecht, Múnich, n. 6, 2018, p. 231-232. El autor se lamenta de que no se acompañe a la ley de una mayor dotación de personal para hacer frente al esfuerzo extra que va a suponer su aplicación a la Administración de Justicia. Sobre los problemas prácticos causados por esta premura: REH, Nicole. Praxisprobleme im Umgang mit dem neuen Recht der Vermögensabschöpfung aus staatsanwaltschaftlicher Sicht. Neue Zeitschrift für Wirtschafts-, Steuer- und Unternehmensstrafrecht, Múnich, n. 1, 2018, p. 20-25.

24 BITTMAN, Folker. Das Gesetz zur Reform der strafrechtlichen Vermögensabschöpfung in der Rechtsprechung - Teil 1/2. Neue Zeitschrift für Strafrecht, Múnich, n. 7, 2019, p. 383-385. 
órganos judiciales han manifestado sus dudas por transgredir la prohibición de la retroactividad de la norma penal desfavorable ${ }^{25}$, otros estiman que es perfectamente constitucional, ya que el decomiso no puede ser considerado sanción a los efectos de esta prohibición ${ }^{26}$. El Tribunal Federal de Justicia (Bundesgerichtshof, en adelante BGH) en un principio consideró que la norma no colisionaba con el principio nulla poena sine lege praevia recogido en el art. 103.2 GG dada la naturaleza "restitutiva" del decomiso ${ }^{27}$. Sin embargo, posteriormente viró de postura por su posible incompatibilidad con el principio de irretroactividad, por lo que elevó la cuestión al Tribunal Constitucional Federal (Bundesverfassungsgericht, en adelante BVerfG) ${ }^{28}$, pendiente de resolución. En concreto, considera incompatible el art. 316h EGStGB con los principios propios del Estado de Derecho, como la seguridad jurídica, en relación con el nuevo ámbito de aplicación del decomiso ampliado ( $\$ 73 \mathrm{a} \mathrm{StGB}$ ) y del decomiso independiente ampliado (\$76a 4 StGB $)^{29}$, aspecto que desarrollaremos infra.

Esto nos lleva a hacer una mínima referencia a la naturaleza jurídica del decomiso en Alemania, que el código penal define simplemente como "medida” (Maßnahme, § 11.8 StGB). Cuando de ganancias del delito se trata, el legislador alemán considera que esta figura no tiene una naturaleza penal (en el sentido de punitiva) sino restitutiva o compensatoria, de manera similar al concepto de enriquecimiento injusto ${ }^{30}$ regulado en el código civil ${ }^{31}$

25 OLG München (5. Strafsenat), Urteil v. 19.07.2018 - 5 OLG 15 Ss 539/17; LG Berlin, Beschluss v. 08.11.2017 - (526 KLs) 244 Js 863/14 (10/16).

BGH Urteil. v. 15.5.2018 - 1 StR 651/17; BGH Beschluss v. 19.12.2018 - 3 StR $347 / 18$.

27

BGH, Urteil v. 10.04.2018 - 5 StR 611/17. BÖSE, Martin; WEYER, Vera. Germany. Improving Confiscation Procedures in the European Union. Nápoles, 2019, p. 261.

28 BGH, Beschluss v. 7.3.2019 - 3 StR 192/18. BÖSE, Martin; WEYER, Vera. Germany. Improving Confiscation Procedures in the European Union. Nápoles, 2019, p. 261.

BGH Beschluss v. 7.3.2019 - 3 StR 192/18

30 Tal y como se califica en el proyecto de ley, BT-Drucks. 18/9525, p. 48. Esta es la postura de autores como GRACIA MARTÍN, Luis. Lecciones de consecuencias jurídicas del delito ( $5^{\mathrm{a}}$ Ed.). Valencia, 2016, p. 487.

31 A diferencia del caso español, donde el enriquecimiento injusto se trata de una construcción jurisprudencial. 
(§ 812 y ss. Bürgerliches Gesetzbuch, en adelante BGB). Estas consideraciones ya las había realizado previamente el Tribunal Constitucional Federal que, además, estableció que el decomiso de ganancias tiene la finalidad de desincentivar la delincuencia con ánimo de lucro, además de afianzar la confianza de la ciudadanía en la inviolabilidad de la ley ${ }^{32}$.

La doctrina habla de una medida sui generis con una función reequilibradora de la situación patrimonial legal ${ }^{33}$. No obstante, como sucede en otros ordenamientos del ámbito europeo, también se ha discutido en qué rama del ordenamiento se debe incardinar el decomiso de ganancias, debatiéndose entre lo penal, lo civil o lo administrativo, aunque compartimos la opinión de SALIGER de que no existen modelos puros, sino formas mixtas, que comparten características de unos y otros ${ }^{34}$ : el carácter de consecuencia jurídica del delito, la orientación reparadora o compensatoria, que restituye el sistema económico lícito, el uso de indicios y de balance de probabilidades, pero también la orientación preventiva y disuasoria de nuevos delitos.

En general, la aplicación del decomiso no se basa en un juicio de culpabilidad ni de peligrosidad del sujeto, pero sí en la constatación de la comisión de un hecho tipificado como delito. El foco de atención no es tanto la posición de la persona respecto a la comisión de este hecho, sino la relación de los bienes con el mismo. Sin embargo, esto no implica que el decomiso no deba ser reconocido como una categoría más de la intervención penal, ya que en todo momento el Estado actúa investido de su ius puniendi, tomando la titularidad de unos bienes sobre los que no tiene ningún derecho previo ${ }^{35}$. Centrándonos en el decomiso de ganancias, pese a su función de restitución del orden patrimonial lícito,

32 BVerfG, Beschluss v. 14.01.2004 (2 BvR 564/95). KÖHLER, Marcus. 3. Unternehmensstrafrechtliche Tage, Neue Zeitschrift für Wirtschafts-, Steuer- und Unternehmensstrafrecht, Múnich, n. 6, 2018, p. 226.

33 KÖHLER, Marcus. Die Reform der strafrechtlichen Vermögensabschöpfung - Teil 1/2 - Überblick und Normverständnis für die Rechtspraxis. Neue Zeitschrift für Strafrech, Múnich, n. 9, 2017, p. 498.

34 SALIGER, Frank. Grundfragen der Vermögensabschöpfung. Zeitschrift für die gesamte Strafrechtswissenschaft, Berlín, v. 129, n. 4, 2017, p. 1001-1003.

35 GASCÓN INCHAUSTI, Fernando. El decomiso transfronterizo de bienes. Madrid: Colex, 2007, p. 30-31; MATA BARRANCO, Norberto Javier de la. El fundamento del decomiso como "consecuencia" del delito: naturaleza jurídica 
no creemos que lo más correcto sea hablar de restitución o compensación, en la medida en que el Estado no tiene un derecho preexistente sobre los bienes que decomisa, y que la función de "indemnización a la sociedad" la cumple el uso social que se le de a los bienes, y no el decomiso per se $e^{36}$.

Lo que sí tiene es un innegable efecto disuasorio y, por tanto, preventivo: si tomamos a un individuo racional, al ponderar los pros y los contras de su actuación, la recompensa que obtendrá y los riesgos a los que se enfrenta, el sujeto cometerá el delito cuando los beneficios sean mayores que los riesgos. Aquí entra en juego el decomiso de ganancias como medida disuasiva que minimiza las posibilidades de obtener un beneficio del delito ${ }^{37}$.

En Alemania tradicionalmente han existido dos figuras según el objeto del que se tratara ${ }^{38}$. Esta diferencia ha desaparecido: para homogeneizar la nomenclatura con los instrumentos europeos e internacionales se ha eliminado toda referencia al Verfall y generalizado el nombre de Einziehung (art. 1.1 de la ley de 13 de abril de 2017). No obstante, esta unificación terminológica se queda en lo formal y se mantienen sendos regímenes para las ganancias (Einziehung von Taterträgen, §§ 73 ff. StGB) y el resto de los objetos relacionados con el delito (Einziehung von Tatprodukten, Tatmitteln und Tatobjekten, $\S \S 74 \mathrm{ff}$. StGB).

confusa, pero objetivo claramente punitivo. Estudios de Derecho Penal. Homenaje al profesor Santiago Mir Puig. Buenos Aires, 2017, p. 939-948.

Desarrollamos la cuestión en CARRILLO DEL TESO, Ana E., Decomiso y recuperación de activos en el sistema penal español, Valencia, 2018, p. 142 y ss.

BLANCO CORDERO, Isidoro. Armonización en la UE de los delitos de corrupción. El caso de España. European inklings II. Armonización penal en Europa, n. 2, 2013, p. 153-155.

Mientras que el Verfall, que podríamos traducir como "caducidad" o "vencimiento", se correspondía con el decomiso de las ganancias o el producto del delito; el Einziehung, que podría traducirse como decomiso o confiscación, era la figura correspondiente a instrumentos, efectos y objetos del delito. En castellano, entre otros, AGUADO CORREA, Teresa. El comiso. Madrid, 2000; la traducción de JESCHECK, Hans-Heinrich; WEIGEND, Thomas. Tratado de Derecho Penal, Granada, 2002. Más recientemente: ROIG TORRES, Margarita. La regulación del comiso. El modelo alemán y la reciente reforma española. Estudios Penales y Criminológicos, Santiago de Compostela, v. XXXVI, 2017, p. 547-604 y ROIG TORRES, Margarita. El comiso como estrategia frente a la corrupción en Alemania: interpretación jurisprudencial. Estudios Penales y Criminológicos, Santiago de Compostela, v. XXXVIII, 2018, p. 547-604. 
Esta es una virtud de la regulación alemana de la que nos hemos declarado partidarios en otras ocasiones. ¿Por qué? En primer lugar, porque el decomiso no se trata de una figura unitaria, sino de una categoría que ampara figuras con diferente naturaleza y características según el objeto al que afecten, por lo que diferenciar sus regímenes redunda en una mayor claridad y racionalidad normativa. Además, permite acotar las modernas formas de decomiso, como el decomiso ampliado, al ámbito material que le es propio, ya que la política criminal de recuperación de activos lo que busca es neutralizar las ganancias del delito; aunque lamentablemente esta capacidad de contención se ha visto anulada por el desmesurado afán del legislador alemán de ponerse al día con esta estrategia ${ }^{39}$.

\section{LAS "LUCES" DE la ReForma: SOlUCIONES a ANTIGUOS PROBLEMAS PRÁCTICOS}

\subsection{LAS VÍCTIMAS ANTE EL DECOMISO}

Uno de los grandes problemas que buscaba solucionar el legislador alemán ${ }^{40}$ es la devolución de los bienes a las víctimas o los perjudicados por el delito ${ }^{41}$. El principal problema del régimen anterior era que el decomiso de ganancias solo era aplicable cuando se trataba de delitos

39 CARRILLO DEL TESO, Ana E., Decomiso y recuperación de activos en el sistema penal español, Valencia, 2018, p. 131-133 sobre el problema de la confusión terminológica acerca de los objetos decomisables en el Código Penal español y p. 165-168.

40 Muy crítico con esta reforma, por no observar ninguna mejora para las víctimas, BARRETTO DA ROSA, Steffen. Die Reform der Vermögensabschöpfung: Offene Fragen des neuen Sicherstellungsrechts. Neue Zeitschrift für Wirtschafts-, Steuer- und Unternehmensstrafrecht, Múnich, n. 6, 2018, p. 215-216. También formuló críticas respecto al proyecto de ley DIERLAMM, Alfred. Der Referentenentwurf zur Reform der strafrechtlichen Vermögensabschöpfung - eine Mogelpackung! Strafverteidiger, vol. 36, n. 8, 2016, p. I-II.

41 Cuando hablamos de víctima, nos referimos a la persona física que haya sufrido un daño o perjuicio, en especial lesiones físicas o mentales, daños emocionales o un perjuicio económico, directamente causado por una infracción penal, o sus familiares más cercanos en caso de fallecimiento. Por otro lado, perjudicado es quien se ve dañado por circunstancias que acompañan o derivan de su comisión pero que no es sujeto pasivo del delito. 
contra bienes jurídicos colectivos o difusos. Si había una víctima individual que pudiese reclamar un derecho (pensemos en un robo, un hurto o una estafa común) el decomiso quedaba excluido (antiguo § 73.1 StGB, segunda frase $\mathrm{e}^{42}$ ) y la víctima debía ejercer una acción civil para reclamar la responsabilidad ex delicto.

Lo anterior, sumado a que en Alemania la acumulación de la acción civil al proceso penal principal es una rara avis ${ }^{43}$, hacía que la recuperación o la compensación fuese todo un calvario judicial, cuando no terminaba siendo de imposible satisfacción. Aparte, en las causas en las que había varios perjudicados, estos pasaban a convertirse en competidores entre sí, ya que no se producía un reparto equitativo de los fondos o los bienes con los que contase el delincuente ${ }^{44}$, sino que aquel cuya reclamación fuese resuelta antes en el proceso civil tenía mejores opciones de ver satisfecha su pretensión, situación esta que fue bautizada, muy ilustrativamente, con el nombre de "carrera de galgos" (Windhundrennen) ${ }^{45}$.

Con el propósito de solventar un panorama tan contraproducente, la nueva redacción elimina esta limitación, de manera que ahora cualquier beneficio derivado de la comisión de un delito puede ser decomisado, sea el delito que sea, en virtud del nuevo § 73 StGB: si el autor o el partícipe ha obtenido algo del acto ilícito, el tribunal ordenará su decomiso; lo mismo sucede con los beneficios derivados de este producto del delito [§ 73 (1) y (2) StGB]. En ambos casos de trata de una norma imperativa, lo que no sucede con los objetos que el autor o partícipe haya obtenido mediante la venta del objeto obtenido o como compensación por su destrucción, daño o confiscación o sobre la base de un derecho obtenido, en cuyo caso el decomiso es potestativo [§ 73 (3) StGB].

42 SCHÖNKE, Adolf; SCHRÖDER, Horst. Siebenter Titel. Einziehung. Vorbemerkungen. Strafgesetzbuch Kommentar (30 ed), Múnich, 2019, rn. 7.

43 En este punto conviene aclarar que la acumulación de la acción civil sí es una posibilidad contemplada en el Código Procesal Penal, pero el juez tiene el poder discrecional de rechazarlo, y suele hacerlo, en especial por la falta de adecuación de esta acción con el proceso penal, por los diferentes estándares de prueba, o si va a retrasar considerablemente el procedimiento, § 406.1 StPO.

44 Derivados o no del delito, recordemos que estamos hablando de responsabilidad civil, que va más allá de la restitución del bien

45 Así lo recoge el propio legislador en el proyecto de ley. BT-Drucks. 18/9525, p. 1. 
En cuanto a la compensación a víctimas y perjudicados, se abren varias vías. En caso de tratarse del producto directamente obtenido del delito, conforme al $\S 459 \mathrm{~h} 1 \mathrm{StPO}$, con la sentencia firme la propiedad se transfiere al Estado y, posteriormente, se devolverá a los perjudicados ${ }^{46} \mathrm{O}$ sus sucesores. Si el propietario del bien o víctima es desconocido o no se manifiesta en los seis meses siguientes al anuncio público del decomiso, el bien pasa definitivamente a formar parte de los fondos del Estado ( $\$ 75.1$ in fine StGB). Además, se aclara que, hasta que se transfiera efectivamente la propiedad o el derecho, la orden de decomiso tiene el efecto de una prohibición de disposición en el sentido del § 136 BGB $^{47}$ (§ 75.4 StGB).

Si el bien ya no está en posesión del autor el procedimiento es más complejo: en tal caso, habrán de incautarse provisionalmente otros bienes del autor que aseguren un previsible decomiso por valor equivalente ( $\S 111 \mathrm{e} \mathrm{StPO}{ }^{48}$ ). Entonces se realizarán los bienes incautados y, conforme al $\S 459 \mathrm{~h} 2 \mathrm{StPO}$, el producto generado se abonará a la persona agraviada o su sucesor. Si el producto cubre los daños a todas las víctimas, no hay mayor problema, pero puede ocurrir que haya varias personas agraviadas y el valor de los bienes embargados o del producto generado por su realización no sea suficiente para satisfacer todos sus

46 Sobre este nuevo modelo de compensación, v. MEIßNER, Markus. Das neue Modell der Opferentschädigung - aus Sicht eines (dritt)betroffenen Unternehmens. Neue Zeitschrift für Wirtschafts-, Steuer- und Unternehmensstrafrecht, Múnich, n. 6, 2018, p. 239-245.

47 Este precepto, sobre la prohibición de disposición dictada por un tribunal o cualquier otra autoridad dentro de su competencia, a su vez se remite al § 135 $\mathrm{BGB}$, sobre la prohibición legal de disposición. En esencia, si la disposición de una cosa viola una prohibición de disposición, es ineficaz.

48 Los $\S \S 111$ b y ss. StPO regulan un amplio abanico de medidas provisionales para asegurar futuros decomisos, que pueden ser decretadas, no solo por jueces y tribunales, sino también por el Ministerio Fiscal (aunque deberá pedir una confirmación judicial en el plazo de una semana, § 111j StPO). La nueva regulación de las medidas cautelares es criticada por suponer una merma en los derechos del acusado: al haberse eliminado el requisito previo del examen de una situación sospechosa se abre la puerta a la adopción de estas medidas en caso de mera sospecha, medidas que pueden ser mantenidas largos periodos de tiempo y que virtualmente pueden afectar a todo el patrimonio del acusado. Así en KÖLLNER, Rolf. E.; MÜCK, Jörg. Reform der strafrechtlichen Vermögensabschöpfung. Neue Zeitschrift für Insolvenz- und Sanierungsrecht, n. 15-16, 2017, p. 598. 
derechos al pago de una suma de dinero. En ese caso, previa petición ante el Ministerio Fiscal, este presentará una solicitud de apertura de un procedimiento de insolvencia sobre los bienes del deudor ( $\$ 111$ i.2 StPO). No obstante, se han planteado serias dudas acerca de la funcionalidad práctica de esta nueva regulación, ya que los perjudicados van a tener que esperar a la resolución firme del caso para resolver su situación, no van a tener una vía individual para plantear su pretensión, y pueden jugar en contra los plazos de prescripción civiles, especialmente en los procesos en los que el decomiso se reserve para un procedimiento posterior $^{49}$ (ver infra).

El juego de la acción civil de la víctima con el decomiso es muy interesante, pues en caso de interponerse puede excluir este último. De acuerdo con el § 73e StGB, el decomiso de ganancias ( $\S \S 73$ a 73c StGB) no se podrá aplicar en la medida en que se extinga la reclamación de la parte perjudicada para que se le devuelva el objeto obtenido o para que se le indemnice con una suma de dinero equivalente. Para delimitar cuando ocurre esto tenemos que remitirnos al código civil: esto sucede si el destinatario del decomiso procede a pagar lo adeudado a la víctima (§ 362 BGB) o si la parte perjudicada renuncia (§ 397 BGB). La exclusión del decomiso se puede dar tanto en la fase de decisión como en la de ejecución del decomiso ${ }^{50}$.

Estas previsiones pretenden incentivar la compensación voluntaria por parte del infractor y, a su vez, evitar que sufra un doble gravamen por el Estado y la parte perjudicada ${ }^{51}$ (cuando se trata del decomiso de una cantidad por valor equivalente). No obstante, en el caso de que se hayan producido beneficios indirectos (ganancias del

49 KÖLLNER, Rolf. E.; MÜCK, Jörg. Reform der strafrechtlichen Vermögensabschöpfung. Neue Zeitschrift für Insolvenz- und Sanierungsrecht, n. 15-16, 2017, p. 597.

50 En virtud del $\S 459$ g 4 StPO: el tribunal ordenará que se impida la ejecución de la confiscación según los $\S \S 73$ a 73c StGB al extinguirse el derecho que la persona agraviada adquirió, en virtud del delito, a la restitución de lo obtenido o al pago de una suma de dinero igual al valor de lo obtenido.

51 SCHÖNKE, Adolf; SCHRÖDER, Horst. § 73 Einziehung von Taterträgen bei Tätern und Teilnehmern. Strafgesetzbuch Kommentar ( $30^{\mathrm{a}}$ ed), Múnich, 2019 , rn. 24. 
delito que no entran dentro del derecho de reclamación de la víctima), estos no quedarían afectados por esta norma ${ }^{52}$.

\subsection{LA MATIZACIÓN DEL PRINCIPIO DE GANANCIAS BRUTAS}

Otro de los puntos fuertes de la reforma es la previsión para el cálculo del valor de las ganancias. Nos estamos refiriendo a la célebre dicotomía entre el principio de ganancias brutas (Bruttoprinzip) y el principio de ganancias netas (Nettoprinzip), que tanta literatura ha generado, y que se ha extendido más allá de las fronteras alemanas ${ }^{53}$; esto es, si a la hora de decomisar el producto del delito, o su valor, deben o no descontarse los gastos en que hubiera incurrido el autor o partícipe para la comisión del delito.

A principios de los años 90 se modificó la redacción del $\S 73$ StGB para sustituir la referencia al decomiso de la ventaja o beneficio patrimonial (Vermögensvorteil), sobre el que se sustentaba el Nettoprinzip, por el abstracto etwas erlangten o "algo obtenido", base del Bruttoprinzip. Mediante esta modificación se entendió que el legislador abrazaba el principio de ganancias brutas, ya que por ventaja patrimonial se entendía únicamente el plus que el autor había obtenido del delito, por lo que había que restar los gastos en que hubiera incurrido para su comisión. Sin embargo, ese "algo obtenido" se interpretó como la totalidad del producto del delito, sin ningún tipo de operación de descuento. No toda la doctrina vio la adopción del Bruttoprinzip con buenos ojos: para algunos autores suponía la conversión del decomiso de ganancias en una sanción penal, dado que iba más allá de la restitución de la situación

52 KÖHLER, Marcus; BURKHARD, Christiane. Die Reform der strafrechtlichen Vermögensabschöpfung - Teil 2/2. Neue Zeitschrift für Strafrech, Múnich, n. 12, 2017, p. 673. Los autores ponen el ejemplo de aquel que roba un reloj y posteriormente lo vende, siendo el receptador el que devuelve el reloj a la víctima. En este caso, la cantidad que el autor del robo obtuvo por la venta podría ser decomisada, no entraría dentro del supuesto del \& 73 e (1) StGB.

53 Un panorama general del derecho comparado en BLANCO CORDERO, Isidoro. El comiso de ganancias, ¿brutas o netas?. Diario La Ley, Diario La Ley, Madrid, n. 7569, 2011, p. 1-45. 
previa a la comisión del delito y podía afectar a patrimonio lícito del autor de los hechos delictivos ${ }^{54}$.

Lo que en su día se modificó con una sutileza lingüística, en esta ocasión ha requerido una regulación expresa, entre otras cosas debido a que las salas penales del Tribunal Federal de Justicia no se ponían de acuerdo a la hora de fijar su interpretación ${ }^{55} \mathrm{y}$, además, porque, aunque había casos muy claros, como el narcotráfico, otros presentaban serias dudas, por ejemplo, qué se debe decomisar a quien ha obtenido un contrato a través de prácticas delictivas (habitualmente, a través del cohecho), pero lo ha ejecutado en todos sus términos cumpliendo con la legalidad ${ }^{56}$.

Ante la falta de un criterio legal específico para esos supuestos, surgieron diferentes soluciones en doctrina y jurisprudencia ${ }^{57}$. La primera fue optar por una interpretación amplia del principio de ganancias brutas y decomisar el valor total de la adjudicación del contrato, lo que incluye los pagos ingresados por los trabajos de ejecución. Esta postura fue criticada por su carácter desproporcionado y porque, entre otros efectos, paradójicamente provocaba un enriquecimiento de la Administración Pública, que se veía beneficiada por la corrupción de sus funcionarios ${ }^{58}$.

54 Referencias en RÖNNAU, Thomas. Vermögensabschöpfung in der Praxis, Múnich, 2003, p. 189; o BÖSE, Martin; WEYER, Vera. Germany. Improving Confiscation Procedures in the European Union. Nápoles, 2019, p. 251.

55 SALIGER, Frank. Grundfragen der Vermögensabschöpfung. Zeitschrift für die gesamte Strafrechtswissenschaft, Berlín, v. 129, n. 4, 2017, p. 1011; KORTE, Matthias. Grundzüge der Reform der Vermögensabschöpfung. Neue Zeitschrift für Wirtschafts-, Steuer- und Unternehmensstrafrecht, Múnich, n. 6, 2018, p. 234-

56 Este debate llevaba tiempo presente en la doctrina alemana, tal como expuso BLANCO CORDERO, Isidoro. La aplicación del comiso en caso de adjudicación de contratos públicos obtenida mediante soborno de funcionarios públicos. Estudios Penales y Criminológicos, Santiago de Compostela, v. XXVII, 2007, p. 43-60. Sobre el estado de la cuestión actualizado hasta la reforma, HEINE, Sonja. Zum Verfall bei Austauschverträgen: Wider die Aushöhlung des Bruttoprinzips, Neue Zeitschrift für Strafrecht, Múnich, n. 3, 2015, p. 127136 , contraria a la matización jurisprudencial del principio de ganancias brutas en relación con los contratos obtenidos delictivamente.

57 Nos remitimos a BLANCO CORDERO, Isidoro. El decomiso de las ganancias de la corrupción. Revista Eletrônica de Direito Penal AIDP-GB, Río de Janeiro, v. 1, n. 1, 2013, p. 128-135.

58 BLANCO CORDERO, Isidoro. La aplicación del comiso en caso de adjudicación de contratos públicos obtenida mediante soborno de funcionarios 
Frente a esta interpretación, se propuso otra restrictiva, conforme a la cual solo se habrían de decomisar las ganancias obtenidas fruto de la práctica ilícita con la que se consiguió la adjudicación del contrato, es decir, las comisiones ilegales que se han pagado al funcionario, opción también criticada porque supone que quien corrompe puede disfrutar plenamente de todo el beneficio obtenido por la comisión de un delito.

La opción intermedia entre ambas posiciones fue la de decomisar la ventaja económica derivada de la obtención de esa adjudicación. Esta postura presentaba el problema del cálculo de esa ventaja patrimonial, ante el cual se presentaron dos opciones: la primera, decomisar el valor total de la adjudicación, descontando los gastos de la ejecución del contrato. La segunda opción, dado que lo que obtiene el corruptor es el derecho a la ejecución del contrato, era decomisar las ganancias que se esperaba obtener.

Ante la falta de una interpretación jurisprudencial unificada, la solución a la que se ha llegado es la de aplicar un principio bruto matizado ${ }^{59}$. Aunque la redacción del § 73d StGB, relativo a la estimación del valor del producto, parece apostar prima facie por el principio neto, pronto vemos que dista de ser así: nos dice que los gastos del autor, del participe o de otra persona se deducirán al determinar el valor de los bienes obtenidos. Lo que no se tendrá en cuenta, sin embargo, es lo que se haya gastado o utilizado para la comisión del delito o para su preparación en la medida en que no se trate de gastos para el cumplimiento de una responsabilidad frente a la parte perjudicada.

Así pues, los gastos en que los incurra el autor solo serán deducidos si son legítimos, como contraprestaciones contractuales pagadas legalmente. Sin embargo, en supuestos de narcotráfico, en los que

públicos. Estudios Penales y Criminológicos, Santiago de Compostela, v. XXVII, 2007, p. 46-48.

59 Ampliamente, RÜBENSTAHL, Markus. Bruttoabschöpfung nach neuem Recht - alte und neue Probleme (Die Perspektive eines Strafverteidigers). Neue Zeitschrift für Wirtschafts-, Steuer- und Unternehmensstrafrecht, Múnich, n. 6, 2018, p. 255-261 y SCHÄUBLE, Johannes; PANANIS, Panos. Subjektive Beschränkungen des Bruttoprinzips nach neuem Einziehungsrecht ( $\$ 73 \mathrm{~d}$ Abs. 1 StGB). Neue Zeitschrift für Strafrecht, Múnich, n. 2, 2019, p. 65-72. 
se ha realizado un gasto en una mercancía de comercio prohibido, este no se podrá deducir. Lo curioso es que los partidarios del Nettoprinzip radical parten de una naturaleza jurídica "civil” o análoga al instituto del enriquecimiento injusto, por lo que se ha de deducir en todo caso el gasto realizado para evitar cualquier mácula de carácter sancionatorio en el decomiso ${ }^{60}$. Pero es precisamente en la regulación del enriquecimiento injusto del código civil alemán donde nace la prohibición de deducir los gastos ilícitos, ya que el § 817 s. 2 BGB establece la pérdida de la inversión prohibida.

La norma del § 73d StGB parece especialmente indicada para calcular el valor de las ganancias cuando se va a aplicar el decomiso por valor equivalente, pero es de aplicación general para evitar que el decomiso directo pueda tener efectos punitivos. Sobre la determinación de los concretos gastos deducibles, la prohibición de deducción de este artículo se debe aplicar únicamente si el autor invierte deliberadamente en algo prohibido o contrario a la ley. Si actúa negligentemente, no sería aplicable la prohibición, salvo que se trate de delitos que se puedan cometer imprudentemente. Esta norma, ya lo venimos diciendo, va dirigida a la ejecución de contratos sinalagmáticos conseguidos mediante la comisión de un delito. En el caso de que lo entregado como precio sea un objeto determinado, si no se pudiera decomisar por entero, se decomisaría el valor de la cantidad correspondiente ${ }^{61}$. No obstante, se abandona uno de los fines de la adopción del Bruttoprinzip, que era evitar a jueces y tribunales cualquier tipo de cálculo de descuento sobre las ganancias y la prueba de los gastos ${ }^{62}$, algo que, de todas formas, la realidad demostró como inviable.

${ }^{60}$ En España, v. gr., VIZUETA FERNÁNDEZ, Jorge. El comiso de las ganancias provenientes del delito y el de otros bienes equivalentes a éstas. Revista Penal, Barcelona, n. 19, 2007, p. 168-171; o, recientemente, CASTELLVÍ MONTSERRAT, Carlos. Decomisar sin castigar. Utilidad y legitimidad del decomiso de ganancias. InDret, Barcelona, n.1, 2019, p. 55-58.

${ }^{61}$ KÖHLER, Marcus. Die Reform der strafrechtlichen Vermögensabschöpfung - Teil 1/2 - Überblick und Normverständnis für die Rechtspraxis. Neue Zeitschrift für Strafrech, Múnich, n. 9, 2017, p. 506-511.

62 SALIGER, Frank. Grundfragen der Vermögensabschöpfung. Zeitschrift für die gesamte Strafrechtswissenschaft, Berlín, v. 129, n. 4, 2017, p. 1012. 


\subsection{CUESTIONES PROCESALES: SEPARACIÓN DEL PROCEDIMIENTO DE DECOMISO Y PRINCIPIO DE OPORTUNIDAD}

En materia procesal se introduce otra de las novedades que podrían resultar más positivas: la posibilidad de separar, por decisión judicial ${ }^{63}$, la orden del decomiso de la sentencia de condena a fin de reservarla para un segundo procedimiento. Se pretende con ello descongestionar los procesos penales complejos, y procurar la celeridad de la sentencia sobre la responsabilidad penal, especialmente en causas en las que el acusado se encuentra en prisión preventiva ${ }^{64}$, como se especifica en el § 422 StPO. Esta decisión de decomiso a posteriori deberá llevarse a cabo, a más tardar, seis meses después de que la sentencia del proceso principal haya devenido firme ( $\$ 423 \mathrm{StPO}$ ). Consideramos un acierto el establecimiento de un plazo máximo para que se desarrolle este procedimiento subsiguiente, ya que sirve para neutralizar uno de los riesgos que este tipo de procedimientos lleva aparejado: que se ponga en peligro la eficacia del decomiso al postergar indeterminadamente su determinación y ejecución, lo que da margen a la desaparición o distracción de los bienes, si no se ha llevado a cabo la oportuna localización de los bienes y la imposición de medidas cautelares. En este segundo caso, el riesgo es para el afectado por tales medidas (no necesariamente el acusado del delito, pueden ser terceras personas ajenas al mismo), que podrían sufrir una restricción sobre su patrimonio de manera indefinida.

Anudado a lo anterior, vale la pena mentar igualmente la operatividad del principio de oportunidad en el decomiso conforme al $\S 421$ (1) StPO ${ }^{65}$ : el tribunal, con el acuerdo de la fiscalía, puede

63 No se aclara, sin embargo, en qué momento debe tomarse. TEMMING, Dieter. § 422 Abtrennung der Einziehung. Beck'scher Online-Kommentar StPO mit RiStBV und MiStra (36 ${ }^{\mathrm{a}}$ Ed). Múnich, 2020, rn. 4.

64 En los que en ocasiones los jueces se abstenían de imponer el decomiso para acabar antes, Gesetzentwurf Reform der strafrechtlichen Vermögensabschöpfung - Fragen und Antworten -, p. 4.

65 BITTMAN, Folker. Das Gesetz zur Reform der strafrechtlichen Vermögensabschöpfung in der Rechtsprechung - Teil 2/2. Neue Zeitschrift für Strafrecht, Múnich, n. 8, 2019, p. 447-449; RETTKE, Arne. Die Bedeutung der Einziehung gemäß $\S 73$ StGB - Die Aufwertung der strafrechtlichen Vermögensabschöpfung - Teil 1. Neue Zeitschrift für Wirtschafts-, Steuer- und Unternehmensstrafrecht, Múnich, n. 8, 2019, p. 283-287. 
renunciar al decomiso si el valor del producto del delito es insignificante ${ }^{66}$ o bien si el procedimiento requeriría un esfuerzo irrazonable o dificultaría injustificadamente la adopción de una decisión sobre las demás consecuencias jurídicas del acto ${ }^{67}$. En el tercer apartado del mismo artículo se le da la facultad al Ministerio Fiscal durante la fase de instrucción de limitar el proceso al resto de consecuencias legales [§ 421 (3) StPO], es decir, de excluir el decomiso del proceso. Al no establecer ninguna condición, ni referirse tampoco a las circunstancias del primer apartado, parece que la facultad de la fiscalía en esta fase es completamente discrecional, sin embargo, en virtud del § 421 (2) StPO, el tribunal puede ordenar el decomiso en cualquier fase del proceso. Por otro lado, se ha apuntado que por el especial rol del Ministerio Fiscal de garante de la legalidad, está en la obligación de pedir el decomiso siempre que sea posible ${ }^{68}$.

De igual manera, aunque la cláusula de proporcionalidad, o de exclusión del decomiso por excesivo rigor, ha sido eliminada de la

66 Cuestión diferente es determinar qué se entiende por valor insignificante. Dependiendo de la fuente, se habla de $50 €, 150 €, 500 €$ o, incluso, $1000 €$; según la Oficina Federal de Justicia (Bundesamt für Justiz), varía notablemente de unos estados a otros. V. BÖSE, Martin; WEYER, Vera. Germany. Improving Confiscation Procedures in the European Union. Nápoles, 2019, p. 255.

67 Esta opción ha sido utilizada por el Landgericht de Bonn (Beschluss v. 17.03.2020 - 62 KLs 1/19) para no decidir sobre el decomiso de cuatro sociedades de inversión sobre las que pesaban medidas provisionales en la sentencia que puso fin al primer proceso por las transacciones Cum/Ex, un complicado entramado de compra y venta de activos bursátiles con el que se estima que, solo en Alemania, se defraudaron 440 millones de euros al fisco; que fue objeto de la Resolución del Parlamento Europeo sobre el escándalo «cum-ex»: delincuencia financiera y lagunas en el actual marco jurídico (2018/2900(RSP)). El tribunal de Bonn tomó esta decisión por la dificultad de la prueba sobre el decomiso de todos los partícipes, por lo que optó por ordenar en la sentencia (dictada dos días después) únicamente el decomiso de los responsables penales; aunque no descarta la opción de abrir procedimientos independientes de decomiso contra esas empresas, aparte de las vías que tiene la Hacienda Pública para la recuperación, con requisitos menos exigentes que el decomiso en sede penal.

RETTKE, Arne. Die Bedeutung der Einziehung gemäß $\S 73$ StGB - Die Aufwertung der strafrechtlichen Vermögensabschöpfung - Teil 1. Neue Zeitschrift für Wirtschafts-, Steuer- und Unternehmensstrafrecht, Múnich, n. 8, 2019, p. 287. 
regulación del StGB, se ha trasladado a las disposiciones sobre ejecución del StPO: en el $\$ 459 \mathrm{~g}$ (5) se permite denegar la ejecución del decomiso si los bienes a los que se refiere la decisión ya no se encuentran en el patrimonio del afectado o resultaría desproporcionada, aunque se habilita la posibilidad de reanudar esta ejecución si salen a la luz circunstancias que así lo aconsejen.

\section{LAS "SOMBRAs" de la REForma: Aspectos controvertidos}

\subsection{LA ILIMITADA POTESTAD DE DECOMISO AMPLIADO}

Hasta ahora hemos examinado los puntos de la reforma que pueden resultar más positivos, especialmente por facilitar la práctica del decomiso. Pero esta ley también contiene un par de puntos discutibles que cabría catalogar como excesos del legislador en una observación exacerbada del principio crime doesn't pay. En primer lugar, se modifica el decomiso ampliado ${ }^{69}$ para desvincularlo de la comisión previa de un catálogo cerrado de delitos.

Según la nueva redacción del § 73a 1 StGB, si se ha cometido un hecho ilícito ${ }^{70}$, el tribunal ordenará la confiscación de los objetos del delincuente o participante, aun cuando dichos objetos hayan sido obtenidos por otros actos ilícitos; es decir, cualquier delito abre la puerta a la imposición del decomiso ampliado ${ }^{71}$. Al parecer, es la interpretación

69 Cabe recordar que Alemania, junto con Italia, fue uno de los primeros países en regularlo en el año 1992 mediante la Gesetz zur Bekämpfung des illegalen Rauschgifthandels und anderer Erscheinungsformen der Organisierten Kriminalität (OrgKG). Bundesgesetzblatt, Jahrgang 1992, Teil I, Nr. 34 - Tag der Ausgabe: Bonn, den 22 Juli 1992; en Italia, con el Decreto legge n. 306, 8 giugno 1992, pubblicato nella Gazz. Uff. 8 giugno 1992, n. 133 e convertito in legge, con modificazioni, dalla L. 7 agosto 1992, n. 356 - Gazz. Uff. 7 agosto 1992, n. 185.

70 Este hecho ilícito no tiene que ser necesariamente culpable al no tratarse de una pena, SCHÖNKE, Adolf; SCHRÖDER, Horst. § 73a Erweiterte Einziehung von Taterträgen bei T ätern und Teilnehmern. Strafgesetzbuch Kommentar (30ª ed), Múnich: C.H. Beck, 2019, rn. 6.

71 Esto puede suponer un problema de cara al reconocimiento mutuo de resoluciones de decomiso emitidas por Alemania en el ámbito de la Unión Europea. Está pendiente la entrada en vigor del Reglamento (UE) 2018/1805 
que hace el legislador alemán de las exigencias de la Directiva 2014/42/ UE, alegando que tampoco contiene limitación alguna para esta potestad de decomiso y requiere que los Estados extiendan su ámbito de aplicación a todos los delitos dentro del especial ámbito de protección de la Unión Europea $^{72}$, así que ha optado por no delimitar los delitos previos ${ }^{73}$.

Aparte de la modulación de la sentencia para tener en cuenta decomisos anteriores ( $\$ 73 \mathrm{a} 2 \mathrm{StGB}$ ), no se dice nada más. Nada que acote su ámbito de aplicación, más allá de que los bienes tienen que provenir de delitos anteriores que, por supuesto, son desconocidos. Lo único que se dice en los el proyecto de ley es que se deben respetar los requisitos establecidos por el Tribunal Constitucional Federal ${ }^{74}$. En una ya famosa decisión de $2004^{75}$ este tribunal estableció que la asunción del origen ilícito de un bien en el sentido del antiguo § 73d Abs. 1 Satz 1 StGB se justifica si el juez llega a esta conclusión agotando las pruebas disponibles (a lo que se suma otro requisito jurisprudencial, esta vez del Tribunal Federal de Justicia: incluir expresamente la horquilla temporal que se está juzgando en el fallo ${ }^{76}$ ). Pero, en términos de hasta dónde va a llegar la investigación, nos surgen serias dudas sobre si esta desvinculación de un numerus clausus de delitos previos supone que el patrimonio de cualquier procesado va a ser sometido a un test de licitud.

del Parlamento Europeo y del Consejo de 14 de noviembre de 2018 sobre el reconocimiento mutuo de las resoluciones de embargo y decomiso (el 19 de diciembre de 2020, art. 41), que en su art. 3.2 supedita el reconocimiento de resoluciones a la verificación de la doble incriminación cuando se trate de un delito que no aparece listado en el 3.1. Hasta entonces, sigue rigiendo la Decisión Marco 2006/783/JAI del Consejo de 6 de octubre de 2006 relativa a la aplicación del principio de reconocimiento mutuo de resoluciones de decomiso, que en el art. 8.3 permite denegar el reconocimiento o ejecución precisamente por tratarse de un decomiso ampliado que excede el ámbito de aplicación marcado en las normas europeas.

El art. 3 de la Directiva 2014/42/UE al definir el ámbito de aplicación de esta no incluye una lista de delitos, sino que se refiere a los delitos incluidos en una lista de normas europeas.

BT Drucks 18/9525, p. 65; BÖSE, Martin; WEYER, Vera. Germany. Improving Confiscation Procedures in the European Union. Nápoles, 2019, p. 256.

BT Drucks 18/9525, p. 65-66.

BVerfG, Beschluss v. 14.01.2004 (2 BvR 564/95).

BGH NJW 1995, 470. 
Obviamente, no ha faltado quien ha manifestado sus dudas sobre la constitucionalidad de este nuevo decomiso ampliado, especialmente por la proporcionalidad en relación con el derecho de propiedad del art. $14 \mathrm{GG}^{77}$. Esta nueva concepción del decomiso ampliado comporta un problema de falta de fundamentación o justificación de la medida, que siempre había radicado, cuando iba unida a un catálogo de delitos previos, a su imposición en un ámbito muy concreto: el de la criminalidad organizada, aquella contra la que el proceso penal clásico se ve más desarmado, más carente de herramientas suficientes para poder actuar. Así lo han visto siempre los principales tribunales al examinar su compatibilidad con derechos y garantías penales y procesales ${ }^{78}$, e incluso la doctrina alemana que estudió aquella primera regulación tenía muy claro que eran las especiales características de ese tipo de delincuencia las que justificaban una medida

77 SALIGER, Frank. Grundfragen der Vermögensabschöpfung. Zeitschrift für die gesamte Strafrechtswissenschaft, Berlín, v. 129, n. 4, 2017, p. 1019-1022; KÖLLNER, Rolf. E.; MÜCK, Jörg. Reform der strafrechtlichen Vermögensabschöpfung. Neue Zeitschrift für Insolvenz- und Sanierungsrecht, n. 15-16, 2017, p. 598.

78 Ese es el caso del Tribunal Europeo de Derechos Humanos. A pesar de que le parecen contrarias a la presunción de inocencia según el art. 6.2 del Convenio Europeo de Derechos Humanos las decisiones judiciales o declaraciones de una autoridad sobre una persona acusada de un delito que den a entender que el sujeto es culpable antes de que se pruebe de acuerdo con la ley (v. Geerings $v$. The Netherlands, no. 30810/03, §41 ECHR, 1 march 2007), hace una excepción en el caso del decomiso en varios pronunciamientos (Phillips $v$. the United Kingdom, no. 41087/98, § 35, ECHR 2001-VII o Van Offeren $v$. the Netherlands (dec.), no. 19581/04, 5 July 2005). Pero en esos casos, el sujeto fue condenado por delitos de narcotráfico y seguía siendo sospechoso de otros delitos de esa naturaleza; poseía, de manera demostrable, bienes cuya procedencia no se podía establecer; se presumía razonablemente que esos bienes se habían obtenido mediante una actividad ilegal y no había proporcionado una explicación alternativa satisfactoria. Es remarcable que lo primero a lo que se refiere es el tipo de delito que se ha cometido, precisamente uno de esos fenómenos delictivos que son objeto de especial preocupación para la comunidad internacional. Más recientemente, en Gogitidze and others v. Georgia, no. 36862/05, § 107, ECHR, 12 may 2015, en lo que respecta a los bienes que se presume que han sido adquiridos total o parcialmente con el producto de delitos de tráfico de drogas u otras actividades ilícitas de organizaciones mafiosas o delictivas, el Tribunal no vio ningún problema en considerar que las medidas de decomiso son proporcionadas, incluso en ausencia de una condena que establezca la culpabilidad de los acusados. 
de este tipo ${ }^{79}$. Si le quitamos esa premisa de base, la construcción se desmorona. Esta controversia, que aún está por resolver, sirve también para poner de manifiesto el peligro de permitir "medidas desesperadas" ante "situaciones desesperadas": que las disposiciones excepcionales para determinados delitos se terminen convirtiendo en regla de aplicación general, pues una vez que permitimos aminorar garantías y derechos en pos de una mayor eficacia, se torna muy difícil revertir esa erosión.

No obstante, siempre hemos visto problemático el decomiso ampliado, no ya solo por sus efectos, sino conceptualmente. Esta potestad de decomiso se basa en la imposibilidad de probar las concretas actividades de las que provienen los bienes que posee el autor de los hechos enjuiciados. Así pues, esos hechos, imposibles de individualizar, no van a ser perseguidos ni castigados y, ciertamente, este decomiso no es una pena, no supone, en principio, una privación o restricción de derechos o bienes legítimos del sujeto culpable en respuesta a la comisión de un delito, pero sí supone la declaración de que esa persona tiene una forma de vida delictiva ${ }^{80}$. Con todo, no hay que perder de vista que sí hay un riesgo de poder afectar al patrimonio lícito del sujeto contra el que se dirige esta medida ${ }^{81}$.

Son interesantes las consideraciones sobre la compatibilidad del decomiso ampliado con la presunción de inocencia en Alemania, ya que ahí se comprueba que lo que cambia no es tanto cómo se configura

79 PERRON, Walter. Vermögensstrafe und Erweiterter Verfall: Im Spannungsfeld zwischen öffentlichen Strafverfolgungsinteressen und privaten Eigentumsrechten. Juristenzeitung), Tubinga v. 48, n. 19, 1993, p. 920.

80 En este sentido, MAUGERI, Anna Maria. Le moderne sanzioni patrimoniali tra funzionalià e garantismo, Milán, p. 754-755, sostiene que un pronóstico sobre la vida pasada del condenado, que esconde la incapacidad de probar los hechos acontecidos y supone conformarse con meras sospechas, no puede constituir la base de ninguna medida sancionatoria. Ya que no se ha probado la culpabilidad del autor en relación con esos hechos, queda únicamente una sospecha de culpabilidad, y se asemeja a una pena de sospecha. Al final, se acoge una concepción de la culpabilidad por el estilo de vida, porque, aunque se sostenga que el objeto de reproche penal es el delito probado, a esas actividades anteriores se les atribuye el valor de síntomas de la reprochabilidad del acto.

BOUCHT, Johan. Extended Confiscation: Criminal Assets or Criminal Owners? Chasing Criminal Money. Challenges and Perspectives On Asset Recovery in the EU, Oxford; Portland, 2017, p. 136. 
esta potestad, sino el concepto de presunción de inocencia, lo que pone también de relieve el problema de trasladar argumentos sobre la validez de una figura de otro ordenamiento jurídico distinto al nuestro sin tener en cuenta todas las premisas sobre las que se asienta. Si en un concepto estricto o restringido de presunción de inocencia como el germánico entendemos que solo actúa ante la efectiva imposición de una pena ${ }^{82}$, pero no ante otro tipo de sanciones o declaraciones que de alguna manera manifiestan la comisión de un delito, y que no hay efecto punitivo pese a que la medida impuesta afecte al derecho a la propiedad ${ }^{83}$, entonces claro está que no hay afección ninguna. Pero si la presunción de inocencia se entiende como protección ante cualquier declaración de una autoridad o una decisión judicial que refleje la opinión de que el sujeto afectado ha cometido un delito que no ha sido probado, entonces el concepto de decomiso ampliado debe ser cuestionado.

\subsection{LOS NUEVOS PERFILES DEL DECOMISO SIN CONDENA: EL DECOMISO INDEPENDIENTE DE BIENES DE ORIGEN INCIERTO}

El otro punto conflictivo guarda relación con el decomiso independiente (selbständige Einziehung) regulado en los $\S 76 a$ StGB y $\S \$ 435-437$ StPO. Hacía tiempo que se debatía sobre la pertinencia de incluir una forma de decomiso sin condena (non-conviction-based confiscation) en Alemania ${ }^{84}$. Hasta ahora, en virtud del antiguo § 76a (1)

82 De acuerdo con la jurisprudencia alemana, la presunción de inocencia no protege frente a las consecuencias jurídicas que no tengan carácter punitivo, sino que protejan el orden público, BVerwG, Urteil, 20.3.2012 - 5 c 1.11, DVBI 2012, 843, § 45. V. ESSER, Robert. A Civil Asset Recovery Model. The German Perspective and European Human Rights. Non-Conviction-Based Confiscation in Europe, Berlín, 2015, p. 80.

83 ESSER, Robert. A Civil Asset Recovery Model. The German Perspective and European Human Rights. Non-Conviction-Based Confiscation in Europe, Berlín, 2015, p. 83 y ss.

84 V. gr. ESSER, Robert. A Civil Asset Recovery Model. The German Perspective and European Human Rights. Non-Conviction-Based Confiscation in Europe, Berlín, 2015, p. 69-109; VOGEL, Joachim. The Legal Construction that Property Can Do Harm. Reflections of the Rationality and Legitimacy of 'Civil' Forfeiture. Non-Conviction-Based Confiscation in Europe, Berlín, 2015, p. 225-243. 
StGB era posible el decomiso sin condena cuando por razones fácticas no se hubiese podido proceder o condenar a una persona (porque no se conocía al autor de los hechos, no se le podía detener o hubiera huido), pero no por razones de derecho ${ }^{85}$. Había cierta discusión sobre si el fallecimiento debía ser considerado un impedimento fáctico o jurídico aunque la mayoría de autores se posicionaba en contra del decomiso en caso de muerte ${ }^{86}$. Esta es otra de las lagunas colmadas con la reforma de 2017, gracias al § 73b (1) 3.a StGB, que permite el decomiso de bienes derivados del delito a terceros cuando lo hayan obtenido en calidad de herederos; pero también al habilitar el § 76a 2 StGB el decomiso en caso de prescripción del delito.

Por otro lado, en el § 76a (3) sigue vigente la posibilidad de decretar este decomiso cuando el proceso termina anticipadamente en virtud de las facultades tanto del Ministerio Fiscal como del tribunal, por mor del principio de oportunidad, reguladas en el $§ 153$ y ss. StPO. Esta posibilidad de decomiso sin condena hay que ponerla en relación con las medidas de cautelares de los $\S 111$ b y ss. StPO, en concreto con el aseguramiento del decomiso por valor equivalente de una suma de dinero ( $\$ 111$ e StPO), que permite la incautación de los bienes muebles e inmuebles propiedad del investigado "si es razonable asumir que se dan las condiciones para el decomiso" ${ }^{87}$. Estas medidas pueden ser decretadas tanto por el tribunal como por el Ministerio Fiscal si las circunstancias lo exigen ( $\$ 111 \mathrm{j}$ StPO), aunque deberá pedir la confirmación del tribunal en el plazo de una semana.

85 JOECKS, Wolfgang. § 76a Selbständige Anordnung. Münchener Kommentar zum StGB. 3 Auflage, Múnich, 2016, rn. 10-11; SALIGER, Frank. § 76a Selbständige Anordnung. Nomos-Kommentar zum Strafgesetzbuch, 5 Auflage, Baden-Baden: Nomos, 2017, rn. 5-10.

86 Referencias en ESSER, Robert. A Civil Asset Recovery Model. The German Perspective and European Human Rights. Non-Conviction-Based Confiscation in Europe, Berlín, 2015, pp. 75-76.

87 Se han relajado las condiciones para el establecimiento de estas medidas cautelares hasta el punto de que ya no es necesario probar un concreto acto para dificultar el futuro decomiso, sino que para negar la medida debe haber razones que permitan suponer la ausencia de una voluntad de manipular los bienes. BITTMAN, Folker. Das Gesetz zur Reform der strafrechtlichen Vermögensabschöpfung in der Rechtsprechung - Teil 2/2. Neue Zeitschrift für Strafrecht, Múnich, n. 8, 2019, p. 451. 
Pero no es a este "decomiso independiente" al que nos referimos como conflictivo, sino al "decomiso independiente ampliado" (erweiterten selbständigen Einziehung ${ }^{88}$, como lo ha denominado la doctrina) o "decomiso de bienes de origen incierto" (Einziehung von Vermögen unklarer Herkunft $\left.{ }^{89}\right)$. En este caso, existe un bien de origen incierto sobre el que el tribunal llega a la conclusión de que procede de la comisión de un delito ${ }^{90}$. Entonces, se dirige contra el bien "resultante de un acto ilícito" incautado en un procedimiento por sospecha de uno de los delitos para los que se habilita, que será decomisado independientemente de que la persona afectada por la incautación sea enjuiciada o condenada por el delito que se investiga.

Esta modalidad de decomiso sí cuenta con un catálogo de delitos en los que se aplica, pero, y aquí reside el aspecto problemático, no concurre condena ni por el "delito de conexión" (como sucede en el decomiso ampliado clásico ${ }^{91}$ ) ni por el delito de origen del bien, que es desconocido. Es decir, ni se ha condenado todavía al sujeto afectado, como en el caso del decomiso ampliado, ni se ha probado la conexión de los bienes con el delito por el que no puede haber sentencia de condena. La lista de delitos se mueve en el marco del terrorismo y el crimen organizado, pero

88 SALIGER, Frank. Grundfragen der Vermögensabschöpfung. Zeitschrift für die gesamte Strafrechtswissenschaft, Berlín, v. 129, n. 4, 2017, p. 1023; MARSTALLER, Marie-Lena; ZIMMERMAN, Till. Non Conviction Based Confiscation in Deutschland? Baden-Baden, 2018, p. 43; KÖHLER, Marcus. Die Reform der strafrechtlichen Vermögensabschöpfung - Teil 1/2 - Überblick und Normverständnis für die Rechtspraxis. Neue Zeitschrift für Strafrech, Múnich, n. 9, 2017, p. 499.

89 MEYER, Frank. Abschöpfung von Vermögen unklarer Herkunft. Neue Zeitschrift für Wirtschafts-, Steuer- und Unternehmensstrafrecht, Múnich, n. 6, 2018, p. 246-250; PELZ, Christian. Abschöpfung von Vermögen unklarer Herkunft in Deutschland. Neue Zeitschrift für Wirtschafts-, Steuer- und Unternehmensstrafrecht, Múnich, n. 6, 2018, p. 251-254.

90 Un ejemplo de su aplicación práctica en LG Hamburg, Beschluss v. 7.3.2019 614 Qs 21/18, BeckRS 2019, 8228; BEUKELMANN, Stephan. Selbstständige Einziehung - Non-conviction-based confiscation. Neue Juristische Wochenschrift Spezial, 2019, p. 376-377.

91 En esta condena por un delito previo tribunales como el Tribunal Europeo de Derechos Humanos basan la compatibilidad del decomiso ampliado con la presunción de inocencia. V. gr. Phillips $v$. the United Kingdom, no. 41087/98, $\S 35$, ECHR 2001-VII. 
también se incluye el blanqueo de capitales, lo que puede actuar como cláusula de apertura ${ }^{92}$.

El tribunal solo tendrá que cerciorarse de que el acto de adquisición (desconocido) no tuvo lugar hace más de treinta años ${ }^{93}$, que es el nuevo plazo de prescripción del decomiso de ganancias ex §76b StGB, por lo que el riesgo de error, de aplicar esta medida a bienes que nada tienen que ver con un delito, aumenta, pues con el paso del tiempo la posibilidad de aportar pruebas sobre el origen se dificulta ${ }^{94}$. No obstante, para desvirtuar estos indicios, el sujeto afectado no tendría por qué probar plenamente su origen, sino que le bastaría con plantear una duda razonable sobre el mismo ${ }^{95}$.

A fin de llegar a la conclusión del origen delictivo, el tribunal puede realizar un "balance de probabilidades", utilizando para ello los indicios regulados en el § 437 StPO. Aparte de la manida "desproporción grave entre el valor del objeto y los ingresos legítimos de la persona de que se trate", podrá tener en cuenta el resultado de la investigación del delito que dio lugar al procedimiento, las circunstancias en que se encontró y se incautó el objeto, y las demás circunstancias personales y económicas de la persona interesada. Estos indicios, en todo caso, tienen que respetar el principio de libre valoración de la prueba del § 261 StPO (el tribunal decidirá el resultado de la actividad probatoria a su discreción y convicción

92 Así lo piensan SALIGER, Frank. Grundfragen der Vermögensabschöpfung. Zeitschrift für die gesamte Strafrechtswissenschaft, Berlín, v. 129, n. 4, 2017, p. 1024 o TRÜG, Gerson. Die Reform der strafrechtlichen Vermögensabschöpfung, Neue Juristische Wochenschrift, Múnich, v. 27, 2017, p. 1916. En contra de las críticas de este último, MEYER, Frank. Die selbstständige Einziehung nach $\S$ 76a StGB-E, oder: Don't bring a knife to a gunfight. Strafverteidiger, Berlín, n. 5, 2017, p. 352.

BT-Drucks 18/11640, p. 83. Sobre este nuevo plazo de prescripción para el decomiso ampliado y el decomiso independiente: HENNECKE, Frank. Ein Ende der Verjährung. Zur Verfassungsmäßigkeit des 'Gesetzes zur Reform der strafrechtlichen Vermögensabschöpfung'. Neue Zeitschrift für Wirtschafts-, Steuer- und Unternehmensstrafrecht, Múnich, n. 4, 2018, p. 121-126. SALIGER, Frank. Grundfragen der Vermögensabschöpfung. Zeitschrift für die gesamte Strafrechtswissenschaft, Berlín, v. 129, n. 4, 2017, p. 1027. 
basándose en todo el contenido de la audiencia) ${ }^{96}$. Según el anteproyecto, el estándar de prueba en estos casos sería similar al aplicado en el proceso civil $^{97}$, aunque algunos autores ven problemática la introducción de estos elementos proceso-civilistas en el proceso penal ${ }^{98}$.

Si el propio legislador admite estar agotando el marco de lo constitucionalmente posible ${ }^{99}$, para la doctrina se ha sobrepasado ${ }^{100}$ : se plantean dudas sobre su conformidad con el derecho a declarar contra uno mismo o con la presunción de inocencia y, sobre todo, se hace hincapié en el excesivo ámbito de aplicación de esta medida, que supera los términos en los que el Tribunal Europeo de Derechos Humanos acepta los procedimientos de decomiso sin condena ${ }^{101}$.

\section{Conclusiones}

Al comienzo de este trabajo nos planteamos una serie de cuestiones que creemos haber respondido en diferente grado. La primera se refería al alcance de la reforma que, ya dijimos, es integral y se planteó en clave de sistema penal, abordando tanto los aspectos sustantivos como procesales. Este es el primer gran punto encomiable de esta ley, ya que no es raro encontrase con reformas en los códigos penales que no van acompañadas de una reforma procesal que las haga operativas. Sin embargo, sí se incurrió en un vicio propio de este tipo de reformas de gran calado en sede penal: no acompañarlas de la necesaria dotación

96 KÖLLNER, Rolf. E.; MÜCK, Jörg. Reform der strafrechtlichen Vermögensabschöpfung. Neue Zeitschrift für Insolvenz- und Sanierungsrecht, n. 15-16, 2017, p. 598, no dudan en catalogar a esta nueva regulación de los § 76a 4 StGB y \& 437 StPO de inversión de la carga de la prueba, de dudosa constitucionalidad.

97 BT-Drucks 18/9525, p. 92.

SALIGER, Frank. Grundfragen der Vermögensabschöpfung. Zeitschrift für die gesamte Strafrechtswissenschaft, Berlín, v. 129, n. 4, 2017, p. 1027.

99 BT-Drucks 18/11640, p. 83.

${ }^{100}$ HINDERER, Patrick; BLECHSCHMITT, Lisa. Die "erweiterte selbständige Einziehung” nach§ 76a Abs. 4 StGB i.V.m. § 437 StPO. Neue Zeitschrift für Wirtschafts-, Steuer- und Unternehmensstrafrecht, Múnich, n. 5, 2018, p. 185.

${ }^{101}$ Por ejemplo, en la citada Gogitidze and others v. Georgia, no. 36862/05, § 107, ECHR, 12 may 2015. 
de medios, especialmente personales, a la Administración de Justicia. Pero, además, fijándonos en los concretos puntos de los que nos hemos ocupado, vemos que no se tratan meros ajustes "cosméticos", sino que las modificaciones lo son en profundidad.

Sobre su relevancia y utilidad, aunque esta necesite tiempo para ser juzgada, creemos que se cumple, especialmente al facilitar la compensación a las víctimas. Con todo, el problema de su situación previa, en nuestra opinión, no venía dado tanto por la configuración del decomiso como de un fallo estructural del proceso penal alemán a la hora de dar entrada a la víctima y a sus pretensiones y de compatibilizar la acción penal y la civil. También es loable la nueva norma para la concreción de las ganancias, que establece una regla de cálculo más precisa frente a los contratos obtenidos mediante prácticas corruptas. Este es, quizá, el punto más interesante en clave de Derecho comparado de cara a su adopción por otros ordenamientos, si bien no logra librar a los tribunales de tener que interpretar este precepto ante las múltiples variables de estos contratos que no contempla.

En cuanto a si cumple los fines que se proponía, en lo que respecta a poner en valor la recuperación de activos la respuesta es, desde luego, afirmativa; de hecho, se ha excedido. En el caso alemán, y como si de la tercera ley de Newton se tratara ("para cada acción existe una reacción igual y opuesta"), a la acción de "no darle la suficiente importancia" a esta política criminal le ha seguido la reacción de ampliar de forma desproporcionada el ámbito de aplicación de las modernas formas de decomiso, hasta el punto de que, en nuestra opinión, se crea un nuevo estatus o estándar en los límites de esta figura.

Quien quiera encontrar soluciones a las grandes dudas o cuestiones doctrinales que suscitan estas modalidades de decomiso en otro Estado -a saber, cuál es la naturaleza del decomiso de ganancias, cuál es su posición en el sistema penal, hasta dónde pueden llegar o hasta qué punto son compatibles con derechos como la presunción de inocencia-se va a encontrar con que todos estamos aquejados de los mismos males y con la misma excusa: la implementación de las medidas ideadas a nivel internacional o supranacional para facilitar la recuperación de activos.

Nos preocupa la deriva que se ha tomado en relación al decomiso ampliado y al decomiso sin condena o independiente aplicable a los bienes 
de origen incierto. Aquí cabe hablar de la discusión sobre la naturaleza del decomiso, que está en la base del desvanecimiento de los límites aplicativos de estas figuras. En los ordenamientos del entorno europeo se repiten los mismos argumentos en la discusión de la doctrina acerca de la admisibilidad de estas formas de decomiso (quizá, ahora, más centrada en el decomiso sin condena) dentro de los parámetros del proceso penal de un Estado de Derecho. En este sentido, tenemos la amarga sensación de que estamos en un impasse: hay dos posiciones sobre esta naturaleza difícilmente reconciliables: verla como una figura de carácter civil, compensatorio, o como una figura que, al operar en el marco del proceso penal, debe observar las garantías que le son propias. Parece que nunca vamos a llegar a discernirla de forma clara, no hay un argumento definitivo. Esta falta de entendimiento es aprovechada por el legislador, que decanta la balanza hacia el eficentismo, encaminándose hacia una potestad de confiscación total.

\section{Bibliografía}

AGUADO CORREA, Teresa. Decomiso: denominador común de la lucha eficaz contra el blanqueo de capitales, la delincuencia organizada y la financiación del terrorismo en la Unión Europea. En: VARGAS, Álvaro; VARGAS LOZANO, Renato (coords.). El lavado de activos y la persecución de bienes de origen ilícito. Bogotá: Universidad Sergio Arboleda, 2017, p. 125-168.

AGUADO CORREA, Teresa. El comiso. Madrid: Edersa, 2000.

BARRETTO DA ROSA, Steffen. Die Reform der Vermögensabschöpfung: Offene Fragen des neuen Sicherstellungsrechts. Neue Zeitschrift für Wirtschafts-, Steuerund Unternehmensstrafrecht, Múnich, n. 6, p. 215-219, 2018.

BEUKELMANN, Stephan. Selbstständige Einziehung - Non-conviction-based confiscation. Neue Juristische Wochenschrift Spezial, p. 376-377, 2019.

BITTMAN, Folker. Das Gesetz zur Reform der strafrechtlichen Vermögensabschöpfung in der Rechtsprechung - Teil 1/2. Neue Zeitschrift für Strafrecht, Múnich, n. 7, 383-398, 2019.

BITTMAN, Folker. Das Gesetz zur Reform der strafrechtlichen Vermögensabschöpfung in der Rechtsprechung - Teil 2/2. Neue Zeitschrift für Strafrecht, Múnich, n. 8, 447-459, 2019. 
BLANCO CORDERO, Isidoro. Armonización en la UE de los delitos de corrupción. El caso de españa. European inklings II. Armonización penal en Europa, n. 2, p. 152-204, 2013.

BLANCO CORDERO, Isidoro. “El comiso de ganancias, ¿brutas o netas?”. Diario La Ley, Madrid, n. 7569, p. 1-45, 2011.

BLANCO CORDERO, Isidoro. "El decomiso de las ganancias de la corrupción". Revista Eletrônica de Direito Penal AIDP-GB, Río de Janeiro, v. 1, n. 1, pp. 112$-145,2013$.

BLANCO CORDERO, Isidoro. "La aplicación del comiso en caso de adjudicación de contratos públicos obtenida mediante soborno de funcionarios públicos”. Estudios Penales y Criminológicos, Santiago de Compostela, vol. XXVIIn. 27, pp. 39-75, 2007.

BÖSE, Martin; WEYER, Vera. "Germany”. En: BERNARDI, Alessandro (ed.);, ROSSI, Francesco (coord.). Improving Confiscation Procedures in t The European Union. Nápoles: Jovene Editore, 2019, pp. 249-285.

BOUCHT, Johan. "Extended Confiscation: Criminal Assets or Criminal Owners?". En LIGETI, Katalin; SIMONATO, Michele (eds.): Chasing Criminal Money. Challenges and Perspectives On Asset Recovery in the EU. Oxford; Portland: Hart Publishing, 2017, pp. 117-137.

CARRILLO DEL TESO, Ana E. Decomiso y recuperación de activos en el sistema penal español. Valencia: Tirant lo Blanch, 2018.

CASTELLVÍ MONTSERRAT, Carlos. "Decomisar sin castigar. Utilidad y legitimidad del decomiso de ganancias”. InDret, Barcelona, n. 1, /2019, p. 1-66.

DIERLAMM, Alfred. Der Referentenentwurf zur Reform der strafrechtlichen Vermögensabschöpfung - eine Mogelpackung! Strafverteidiger, vol. 36, n. 8, p. I-II, 2016. http://dx.doi.org/10.1515/stv-2016-0801

ESSER, Robert. "A Civil Asset Recovery Model. The German Perspective and European Human Rights”. En: RUI, Jon Petter, SIEBER, Ulrich (eds.). Non-Conviction-Based Confiscation in Europe. Berlin: Dunker \& Humblot, 2015, pp. 69-109.

GASCÓN INCHAUSTI, Fernando. El decomiso transfronterizo de bienes. Madrid: Colex, 2007.

GÓMEZ RIVERO, María del Carmen. La recuperación de activos procedentes del delito: ¿hacia el delito de enriquecimiento ilícito? Cuadernos de política criminal, n. 121, p. 201-260, 2017. 
GRACIA MARTÍN, Luis. Lecciones de consecuencias jurídicas del delito ( $5^{\mathrm{a}}$ Ed.). Valencia: Tirant lo Blanch, 2016.

HEINE, Sonja. Zum Verfall bei Austauschverträgen: Wider die Aushöhlung des Bruttoprinzips, Neue Zeitschrift für Strafrecht, Múnich, n. 3, p. 127-136, 2015.

HENNECKE, Frank. Ein Ende der Verjährung. Zur Verfassungsmäßigkeit des 'Gesetzes zur Reform der strafrechtlichen Vermögensabschöpfung'. Neue Zeitschrift für Wirtschafts-, Steuer- und Unternehmensstrafrecht, Múnich, (NZWiSt),n. heft 4, pp. 121-126, 2018.

HINDERER, Patrick; BLECHSCHMITT, Lisa. Die "erweiterte selbständige Einziehung” nach§ 76a Abs. 4 StGB i.V.m. § 437 StPO. Neue Zeitschrift für Wirtschafts-, Steuer- und Unternehmensstrafrecht, Múnich, n. 5, p. 179-185, 2018.

JESCHECK, Hans-Heinrich; WEIGEND, Thomas. (2002): Tratado de Derecho Penal (5 ed.). Granada: Comares, 2002. (Traducción de OLMEDO CARDENETE, Miguel).

JOECKS, Wolfgang. § 76a Selbständige Anordnung. En: JOECKS, Wolfgang; MIEBACH, Klaus (eds.). Münchener Kommentar zum StGB. 3 Auflage, Múnich: Beck, 2016.

JORGE, Guillermo. Los desafíos de recuperar el producto de delitos de corrupción» En JORGE, Guillermo (dir.). Recuperación de activos de la corrupción. Buenos Aires: Del Puerto, 2008, p. XIII-XXXII.

KÖHLER, Marcus; BURKHARD, Christiane. Die Reform der strafrechtlichen Vermögensabschöpfung - Teil 2/2. Neue Zeitschrift für Strafrech, Múnich, n. 12, p. 665-682, 2017.

KÖHLER, Marcus. 3. Unternehmensstrafrechtliche Tage, Neue Zeitschrift für Wirtschafts-, Steuer- und Unternehmensstrafrecht, Múnich, n. 6, pp. 226-230, 2018.

KÖHLER, Marcus. Die Reform der strafrechtlichen Vermögensabschöpfung - Teil 1/2 - Überblick und Normverständnis für die Rechtspraxis. Neue Zeitschrift für Strafrech, Múnich, n. 9, pp. 497-512, 2017.

KORTE, Matthias. Grundzüge der Reform der Vermögensabschöpfung. Neue Zeitschrift für Wirtschafts-, Steuer- und Unternehmensstrafrecht, Múnich, n. 6, p. 231-235, 2018.

MARSTALLER, Marie-Lena;, ZIMMERMAN, Till. Non Conviction Based Confiscation in Deutschland? Baden-Baden: Nomos, 2018. http://dx.doi. org/10.5771/9783845294599 
MATA BARRANCO, Norberto Javier de la. El fundamento del decomiso como "consecuencia" del delito: naturaleza jurídica confusa, pero objetivo claramente punitivo. En: SILVA SÁNCHEZ, Jesús-María; QUERALT JIMÉNEZ, Joan Josep; CORCOY BIDASOLO, Mirentxu; CASTIÑEIRA PALOU, María Teresa (coords.). Estudios de Derecho Penal. Homenaje al profesor Santiago Mir Puig. Buenos Aires: BdeF, 2017, p. 939-948.

MAUGERI, Anna Maria. L'irrefrenabile tendenza espansiva della confisca qualle strumento di lotta contro la criminalità organizzata. En: BARILLARO, Michele (dir.). Criminalità organizzata e sfruttamento delle risorse territoriali, Milán, 2004, p. 97-127.

MAUGERI, Anna Maria. Le moderne sanzioni patrimoniali tra funzionalià e garantismo. Milán: Giuffrè, 2001.

MEIßNER, Markus. Das neue Modell der Opferentschädigung - aus Sicht eines (dritt)betroffenen Unternehmens. Neue Zeitschrift für Wirtschafts-, Steuer- und Unternehmensstrafrecht, Múnich, (NZWiSt),n. 6, pp. 239-245, 2018.

MENDITTO, Francesco. Le confische nella prevenzione e nel contrasto alla criminalità "da profitto" (mafie, corruzione, evasione fiscale). Appunti a margine di alcune proposte di modifica normativa. Diritto Penale Contemporaneo, 2 Febbraio, 2015.

MEYER, Frank. "Reformiert die Rückgewinnungshilfe!” - Denkanstöße für eine Generalüberholung der Vermögensabschöpfung. Zeitschrift für die gesamte Strafrechtswissenschaft, Berlín, v. 127, n. 2, p. 241-283, 2015.

MEYER, Frank. "Abschöpfung von Vermögen unklarer Herkunft”. Neue Zeitschrift für Wirtschafts-, Steuer- und Unternehmensstrafrecht, Múnich, (NZWiSt),n. heft 6, pp. 246-250, 2018.

MEYER, Frank. Die selbstständige Einziehung nach § 76a StGB-E, oder: Don't bring a knife to a gunfight. Strafverteidiger (StV), Berlín, n. 5, pp. 343- - 354, 2017. http://dx.doi.org/10.1515/stv-2017-0509

PELZ, Christian. Abschöpfung von Vermögen unklarer Herkunft in Deutschland. Neue Zeitschrift für Wirtschafts-, Steuer- und Unternehmensstrafrecht, Múnich, (NZWiSt),n. 6, pp. 251-254, 2018.

PERRON, Walter. "Vermögensstrafe und Erweiterter Verfall: Im Spannungsfeld zwischen öffentlichen Strafverfolgungsinteressen und privaten Eigentumsrechten". Juristenzeitung (JZ), Tubinga vol. 48, nnúm. 19, pp. 918-925, 1993. 
REH, Nicole. Praxisprobleme im Umgang mit dem neuen Recht der Vermögensabschöpfung aus staatsanwaltschaftlicher Sicht. Neue Zeitschrift für Wirtschafts-, Steuer- und Unternehmensstrafrecht, Múnich, n. 1, p. 20-25, 2018.

RETTKE, Arne. Die Bedeutung der Einziehung gemäß § 73 StGB - Die Aufwertung der strafrechtlichen Vermögensabschöpfung - Teil 1. Neue Zeitschrift für Wirtschafts-, Steuer- und Unternehmensstrafrecht, Múnich, n. 8, p. 283-287, 2019.

RETTKE, Arne. Die Bedeutung der Einziehung gemäß § 73 StGB - Die Aufwertung der strafrechtlichen Vermögensabschöpfung - Teil 2. Neue Zeitschrift für Wirtschafts-, Steuer- und Unternehmensstrafrecht, Múnich, n. 9, p. 338-342, 2019.

RODRÍGUEZ GARCÍA, Nicolás. El decomiso de activos ilícitos. Cizur Menor: Aranzadi, 2017.

ROIG TORRES, Margarita. El comiso como estrategia frente a la corrupción en Alemania: interpretación jurisprudencial. Estudios Penales y Criminológicos, Santiago de Compostela, vol. XXXVIII, pp. 547-604, 2018.

ROIG TORRES, Margarita. La regulación del comiso. El modelo alemán y la reciente reforma española. Estudios Penales y Criminológicos, Santiago de Compostela, v. XXXVI, pp. 199-279, 2016.

RÖNNAU, Thomas. Vermögensabschöpfung in der Praxis. Múnich: C. H. Beck, 2003

RÜBENSTAHL, Markus. Bruttoabschöpfung nach neuem Recht - alte und neue Probleme (Die Perspektive eines Strafverteidigers). Neue Zeitschrift für Wirtschafts-, Steuer- und Unternehmensstrafrecht, Múnich, n. 6, pp. 255-261, 2018.

SALIGER, Frank. § 76a Selbständige Anordnung. En: KINDHÄUSER, Urs; NEUMANN, Ulfried; PAEFFGEN, Hans-Ullrich (eds.). Nomos-Kommentar zum Strafgesetzbuch, 5 Auflage, Baden-Baden: Nomos, 2017.

SALIGER, Frank. Grundfragen der Vermögensabschöpfung. Zeitschrift für die gesamte Strafrechtswissenschaft, Berlín, v. 129, n. 4, pp. 995-1034, 2017. http:// dx.doi.org/10.1515/zstw-2017-0047

SCHÄUBLE, Johannes; PANANIS, Panos. Subjektive Beschränkungen des Bruttoprinzips nach neuem Einziehungsrecht ( $\$ 73$ d Abs. 1 StGB). Neue Zeitschrift für Strafrecht, Múnich, n. 2, pp. 65- 72, 2019. 
SCHÖNKE, Adolf; SCHRÖDER, Horst. § 73 Einziehung von Taterträgen bei Tätern und Teilnehmern. En: SCHÖNKE, Adolf; SCHRÖDER, Horst. Strafgesetzbuch Kommentar (30ª ed), Múnich: C.H. Beck, 2019.

SCHÖNKE, Adolf; SCHRÖDER, Horst. § 73a Erweiterte Einziehung von Taterträgen bei Tätern und Teilnehmern. En: SCHÖNKE, Adolf; SCHRÖDER, Horst. Strafgesetzbuch Kommentar (30ª ed), Múnich: C.H. Beck, 2019.

SCHÖNKE, Adolf; SCHRÖDER, Horst. Siebenter Titel. Einziehung. Vorbemerkungen. En: SCHÖNKE, Adolf; SCHRÖDER, Horst. Strafgesetzbuch Kommentar (30ª ed), Múnich: C.H. Beck, 2019.

TEMMING, Dieter. § 422 Abtrennung der Einziehung. En: GRAF, Jürgen-Peter (ed.). Beck'scher Online-Kommentar StPO mit RiStBV und MiStra (36 ${ }^{\mathrm{a}}$ Ed). Múnich: C.H. Beck, 2020.

TRÜG, Gerson. Die Reform der strafrechtlichen Vermögensabschöpfung., Neue Juristische Wochenschrift, Múnich, v. 27, pp. 1913-1918, 2017.

VETTORI, B., NICOLA, A. di. The Social Reuse of Confiscated Assets in EU Member States: From Current Experiences to an EU Policy for a "Powered-by-Citizens" Fight Against Crime. En LIGETI, Katalin; SIMONATO, Michele. (eds.). Chasing Criminal Money. Challenges and Perspectives On Asset Recovery in the EU. Oxford; Portland: Hart Publishing, 2017, p. 321-343.

VIZUETA FERNÁNDEZ, Jorge. El comiso de las ganancias provenientes del delito y el de otros bienes equivalentes a éstas. Revista Penal, Barcelona, n. 19, p. 162-178, 2007.

VOGEL, Joachim. The Legal Construction that Property Can Do Harm. Reflections of the Rationality and Legitimacy of 'Civil' Forfeiture. En: RUI, Jon Petter; SIEBER, Ulrich (eds.). Non-Conviction-Based Confiscation in Europe. Berlíin: Dunker \& Humblot, 2015, pp. 225- 243. 


\section{Informações adicionais e declarações dos autores}

Agradecimentos (acknowledgement): al Prof. Dr. Dr. h. c. Walter Perron, al que agradezco su hospitalidad y ayuda con el tema, al Prof. Dr. Isidoro Blanco Cordero, por su ayuda en las gestiones de la estancia, y sus sugerencias, y al Prof. Dr. Nicolás RodríguezGarcía, por su revisión.

Declaração de conflito de interesses (conflict of interest declaration): a autora confirma que não há conflitos de interesse na realização das pesquisas expostas e na redação deste artigo.

Declaração de autoria e especificação das contribuições (declaration of authorship): todas e somente as pessoas que atendem os requisitos de autoria deste artigo estão listadas como autores; a autora se responsabiliza integralmente por este trabalho em sua totalidade.

Declaração de ineditismo e originalidade (declaration of originality): a autora assegura que o texto aqui publicado não foi divulgado anteriormente em outro meio e que futura republicação somente se realizará com a indicação expressa da referência desta publicação original; também atesta que não há plágio de terceiros ou autoplágio.

\section{Dados do processo editorial} (http://www.ibraspp.com.br/revista/index.php/RBDPP/about/editorialPolicies)

- Recebido em: 31/03/2020

- Controle preliminar e verificação de plágio:

- Avaliação 1: 31/03/2020

- Avaliação 2: 02/04/2020

- Avaliação 3: 08/04/2020

- Avaliação 4: 21/04/2020

- Decisão editorial preliminar: 05/05/2020

- Retorno rodada de correções: 20/05/2020

- Decisão editorial final: 29/05/2020

\section{Equipe editorial envolvida}

- Editor-chefe: 1 (VGV)

- Editor-associado: 1 (JJEC)

- Revisores: 4 


\section{COMO CITAR ESTE ARTIGO:}

CARRILLO DEL TESO, Ana E. Recuperación de activos en el sistema penal alemán: luces y sombras del actual régimen de decomiso de ganancias. Revista Brasileira de Direito Processual Penal, Porto Alegre, vol. 6, n. 2, p. 577-616, maio/jun. 2020. https://doi.org/10.22197/rbdpp.v6i2.355 